\title{
Population Pluralism and Natural Selection
}

July 30, 2013

Jacob Stegenga

Forthcoming in The British Journal for the Philosophy of Science

\begin{abstract}
I defend a radical interpretation of biological populations - what I call population pluralism - which holds that there are many ways that a particular grouping of individuals can be related such that the grouping satisfies the conditions necessary for those individuals to evolve together. More constraining accounts of biological populations face empirical counter-examples and conceptual difficulties. One of the most intuitive and frequently employed conditions, causal connectivity - itself beset with numerous difficulties - is best construed by considering the relevant causal relations as 'thick' causal concepts. I argue that the fine-grained causal relations that could constitute membership in a biological population are huge in number and many are manifested by degree, and thus we can construe population membership as being defined by massively multidimensional constructs, the differences between which are largely arbitrary. I end by showing that positions in two recent debates in
\end{abstract}


theoretical biology depend on a view of biological populations at odds with the pluralism defended here.

1 Introduction

2 Biological Population, Broad and Narrow

3 Difficulties with Narrow Biological Population Conditions

3.1 Against G

3.2 Against $S$

3.3 Against $P$

3.4 Against T

4 Causal Connectivity

5 Massively Multidimensional Population Constructs

6 Population Uniqueness and Natural Selection

6.1 Statisticalism and its Discontents

6.2 Price at What Price?

7 Conclusion 


\section{Introduction}

The concept biological population - an evolving group of organisms - can be interpreted broadly or narrowly. Roughly, a broad interpretation holds that a biological population is any grouping of organisms which satisfies certain highly abstract conditions, while a narrow interpretation places more restrictive conditions on a grouping of organisms in order for that grouping to count as a biological population. Here I defend a radically broad interpretation that I call 'population pluralism'.

Ecologists, physiologists, systematists and evolutionary theorists group organisms in a great variety of ways, based on a potentially infinite range of relations - anatomical, genealogical, and morphological, to name a few - and nothing beyond defined group membership unites these disparate ways of grouping organisms. In what follows I am not concerned with how biologists employ the term 'population', nor how biologists generally group individual organisms for their varied research projects. It is entirely uncontroversial for biologists to employ conceptions of 'population' however they see fit. ${ }^{\mathrm{i}}$

Controversy arises, however, regarding a concept of population construed as an evolving group of individuals. What conditions must a grouping of individuals satisfy in order for that grouping to evolve? Numerous answers have been proposed, beginning perhaps with Darwin himself. During the modern synthesis evolutionary biologists began to formulate what has come to be called the 'classical conditions' 
under which evolution can occur. These conditions, prominently associated with (Lewontin [1970]), are usually construed in abstract terms, and constitute a broad interpretation of 'biological population'. Conversely, some argue for more concrete conditions regarding the structure of a grouping of individuals necessary for that grouping to evolve. These concrete conditions constitute narrow interpretations of 'biological population'. I formulate the difference between broad and narrow interpretations of biological populations in $\S 2$, and raise challenges for the conditions employed in narrow interpretations in $\S 3$.

Other unsettled matters in theoretical biology depend on particular conceptions of biological populations, including the ongoing debate regarding the existence of multi-level selection and the more recent debate regarding the interpretation of natural selection as causal or statistical. Below I describe the reliance of certain positions within these debates on a particular-and on my view incorrectinterpretation of 'biological population' as groupings of organisms which are uniquely determined by facts regarding various relations between the respective organisms. The notion of 'biological population' is widely employed in theoretical biology, though it has received much less philosophical analysis than other widely employed concepts in biology, like 'gene', 'species', or 'life'. Developing a compelling interpretation of 'biological population' is, then, a worthwhile endeavor.

The primary contribution of this paper is a defense of a radically broad interpretation of 'biological population', which holds that there are many ways that a group of individuals can be related such that the group satisfies the conditions 
necessary for that group to undergo population dynamics. There are a corresponding number of ways for a biologist to demarcate such a group as a biological population. My principle argument is threefold. First, I note that most of the conditions that constitute the narrow interpretation of 'biological population' face both conceptual difficulties and counter-examples gleaned from the complexity of the biological world (§3). Second, I argue that the most compelling narrow interpretation condition, causal connectivity, is burdened by numerous conceptual difficulties. Regardless, this condition is best construed by considering the relevant causal relations at a fine grain (§4). Third, I argue that the fine-grained causal relations that could constitute membership in a biological population are huge in number and many are manifested by degree, which results in population membership being defined by massively multidimensional constructs, the differences between which are largely arbitrary (§5). The resulting view - population pluralism — is that from a theoretical perspective there are no joints at which a biologist ought naturally carve out populations. ${ }^{\text {ii }}$ Finally, I show that positions in two recent disputes depend on a conception of 'biological population' at odds with the population pluralism defended here $(\S 6)$.

\section{Biological Population, Broad and Narrow}

Classical evolutionary theory provides conditions for a grouping of individuals to undergo population dynamics. Among modern statements of such conditions, 
perhaps the best known is due to (Lewontin [1970]), which holds that evolution occurs when:

1. Different individuals in a population have different morphologies, physiologies, and behaviors (phenotypic variation).

2. Different phenotypes have different rates of survival and reproduction in different environments (differential fitness).

3. There is a correlation between parents and offspring in the contribution of each to future generations (fitness is heritable).

For ease of reference I will refer to these conditions as $V, F$, and $H$, respectively. Lewontin claimed that the three conditions "are necessary and sufficient to account for evolutionary change by natural selection" ([1978] pp. 220). Evolution by natural selection occurs, according to such views, if and only if $V, F$, and $H$ are satisfied by a grouping of individuals. ${ }^{\text {iii }}$ In his discussion of various formulations of these conditions, Godfrey-Smith ([2009]) notes how abstract they are. The kinds of phenotypes that must vary, the measures of fitness, and the mechanisms of heredity are all left open. The notion of population appealed to in such formulations is entirely unspecified, beyond the general requirement that the population be composed of individuals with heritable variations of fitness. This formulation is abstract enough to apply in principle to the evolution of non-biological populations, but when applied to biological organisms this formulation gives us the broad interpretation of 'biological population'. Broad, because $V, F$, and $H$ are abstract and highly underspecified. A grouping of individuals could be related in one of a great 
variety of ways, and as long as $V, F$, and $H$ are satisfied, then, according to a broad interpretation of 'biological population', such a grouping is a biological population and this grouping can undergo evolutionary dynamics.

In contrast, a narrow interpretation of 'biological population' requires conditions that are more constraining than the classical conditions. In what follows I canvas several proposals for such conditions, and in $\S 3$ and $\S 4 \mathrm{I}$ argue that these conditions are beset with numerous conceptual and empirical problems.

Since differential fitness is one of the three classical conditions, and such fitness must be heritable, a prominent view regarding biological populations is that the individuals that constitute a biological population must be related to each other via specific causal relations that constitute or influence reproduction and/or survival. I will call this the causal connectivity $(C)$ constraint on biological populations. Given the relevance of reproduction to each of the three classical conditions, many have assumed that such causes must be associated with reproduction. Dobhzhansky, for instance, claimed that organisms are part of the same population if they are more likely to mate with each other than they are to mate with organisms from other populations. For many population geneticists the smallest group of inter-breeding organisms - panmictic units, or demes — are populations. Similarly, (Sober and Wilson [1998]) argue that if organisms do not engage in interactions which affect fitness, then the organisms do not constitute a biological population (since the organisms would have independent evolutionary fates). ${ }^{\text {iv }}$ To the extent that satisfying $C$ is necessary for satisfying one or more of $V, F$, or $H$, and to the extent that one 
thinks that $V, F$, and $H$ are requirements for biological populations, $C$ is a necessary condition for biological populations. There are, however, reasons to think that $C$ is unnecessary-I explore these in $\S 4$. Moreover, $C$-like $V, F$, and $H$-is highly abstract. Specifying more precisely the causal relations that are relevant for uniting two individuals into the same biological population is a central challenge for an account of 'biological population' which requires $C$. Such a specification forms the basis of population pluralism (§5).

The causal relations that constitute $C$ are sometimes thought to generate an historically extended object when our perspective on the causal relations is sufficiently 'zoomed out' in time and space. Millstein, for instance, argues that biological populations are themselves historical 'individuals', along the lines of the Ghiselin-Hull individuality thesis [(2009]). This condition requires that individuals in a population be united by descent. I will call this the genealogical condition $(G)$.

Another commonly assumed constraint on the notion of 'biological population' is that an evolving group is necessarily sub-species: all members of a population, on this condition, must be members of the same species. Call this the conspecificity condition $(S)$. For instance, Keeton and Gould claim that a population is 'a group of individuals belonging to the same species' ([1986] pp. A41). Even those who defend multi-level selection usually have in mind selection of groups which are sub-

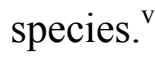


Sometimes a proximity condition $(P)$ is added to a definition of population. Futuyma, for instance, claims that organisms must be part of the same 'well defined geographic region' ([1986] pp. 554).

Many accounts of evolution assume a typology of organisms. This is especially true for the replicator framework, associated with (Dawkins [1976]), (Hull [1980]), and (Lloyd [1988]), to name a few. The rough idea is that organisms that possess traits of different types engage in competition; typehood is transmitted via copying; evolutionary change is simply the change in relative frequency of tokens of the various types. This view, as Godfrey-Smith notes, is not limited to the replicator framework: for example, Sober and Lewontin claim that 'selection theory is about genotypes not genotokens' ([1982] pp. 172). Thus another constraint sometimes placed on the notion of 'biological population' (explicitly or implicitly) is a typology condition $(T)$ : the assumption is that organisms that constitute an evolving group can be sorted into defined types or that the grouped organisms possess traits which can be sorted into defined types.

For ease of reference, Table 1 summarizes the conditions on organism groupings discussed in this section. The order in which I present the conditions is not arbitrary: below I argue that the first three or four conditions listed in the table are plausible necessary requirements for a biological population, at least to the extent that one is committed to the classical approach, but the conditions become less plausible as one goes down the table. 
Table 1. Purported Conditions for Membership in Biological Populations

V Variable Phenotypes

F Fitness Differences

$H \quad$ Heritable Fitness

C Causal Connectivity

$G \quad$ Genealogical Individuality

$S \quad$ Conspecificity

$P \quad$ Geographic Proximity

$T \quad$ Typology

The narrower conditions are presumably meant to be added to the broad conditions, or perhaps are meant to be thought of as more concrete ways in which the broad conditions can be satisfied. Usually a narrow conception of 'biological population' is stated by combining several of the above constraints. For instance, here is Futuyma combining $S, P$, and $G$ (and by implication, $C$ ): a biological population is 'a group of conspecific organisms that occupy a more or less well defined geographic region and exhibit reproductive continuity from generation to generation’ ([1986] pp. 554). As already noted, (Millstein [2009]), drawing on Sober and Futuyma, argues that populations are individuals. Like Futuyma, Millstein does this by combining $S, P$, and $C$. Here is her definition:

Populations (in ecological and evolutionary contexts) consist of at least two conspecific organisms who, over a species-appropriate time span, are mating 
or are engaged in a Darwinian struggle for existence, or both. The population is the largest number of organisms who are causally interconnected.

Organisms who are located in the same spatial area (including recent migrants) are part of the population if and only if they are engaged in causal interactions with other conspecifics. ([2009] pp. 271)

This account of populations is indeed constraining, given that it combines three of the above narrow interpretation conditions. Since this definition is meant to apply to both ecological and evolutionary contexts, presumably Millstein (and Futuyma) implicitly assumes $V, F$, and $H$ when the concept is meant to apply to a group of organisms that undergoes evolutionary dynamics (otherwise the account would be in conflict with the classical conditions, and so would require argument to show that $V$, $F$, and $H$ are not necessary for a group of individuals to co-evolve as a biological population).

As noted above, $C$ is widely thought to be a compelling requirement for biological populations, and many seem to have an intuition that $C$ warrants a narrow interpretation of 'biological population': the facts regarding causal interactions between organisms determine unique biological populations. For example, Millstein claims that 'populations are real entities that act (more or less) as a unit' and this is the case because of 'the presence of causal interactions' ([2010] pp. 66). In $\S 4$ I expose numerous difficulties for $C$. Even if we put aside these difficulties, in $§ 5$ I show that the facts regarding causal interactions between organisms do not determine unique biological populations. Thus, even if one grants $C$ as a requirement for 
biological populations, a broad interpretation of 'biological population' is nevertheless warranted. First, though, I consider and reject the latter four narrow conditions for biological populations.

\section{Difficulties with Narrow Biological Population Conditions}

The genealogical condition $(G)$, proximity condition $(P)$, typology condition $(T)$, and conspecificity condition $(S)$ are all unnecessary constraints on the concept of biological population. These conditions face numerous conceptual and empirical counterexamples.

\subsection{Against $G$}

Suppose a biomedical engineer creates multiple organic automata that can reproduce and that vary with respect to a trait that influences fitness (Swamp Species). These automata have no history prior to their construction, and so no common ancestor. They are, obviously, not united by descent. But once they exist, they satisfy $F, V$, and $H$, and the frequencies of their various traits change over time. We have, then, an evolving group, a biological population, that does not satisfy $G$. Since the grouping undergoes evolutionary dynamics, it has precisely the property of interest. This is a conceptual point: a grouping that can co-evolve need not share a genealogy.

Moreover, any argument that shows that $S$ is not necessary for evolution provides another reason for thinking that $G$ is not necessary for evolution, since on 
many accounts of evolution, $S$ implies $G$ (see footnote 5). Such reasoning would be inconclusive, of course, since there may be some non- $S$ reasons for $G$, but in any case if $S$ were false then there would be one less reason to think that $G$ is true. And $S$ is definitely false.

\subsection{Against $S$}

To require $S$ as a condition of an evolving group of entities is to rule out, by fiat, evolution of groupings of entities which are not part of the same species or are not at the 'level' of organisms of a species, such as groupings of entities which are constitutively sub-species (like genes, mitochondria, or cancer cells) or supra-species (like symbionts, or higher-level taxa themselves). Since the world contains entities that reproduce and that exhibit heritable variation of fitness, and yet are at a scale other than that of organisms (including genes, mitochondria, and buffalo herds), and since the world contains entities that reproduce and that exhibit heritable variation of fitness, and yet are not constituted by organisms of a single species (such as lichens), $S$ is not necessary for a biological population. ${ }^{\text {vi }}$

For an example of entities which form sub-species biological populations, consider genes. Some theorists, such as Dawkins, have famously (albeit controversially) argued that the level of conspecific organisms is irrelevant to understanding evolution, and that evolution should instead be characterized at the level of genes. Although the gene-centric view of evolution has fallen out of popularity, there are some cases in which it is at least plausible to suppose that 
evolution occurs at the level of genes. (Sterelny [2009]) suggests that an example of selection at the level of genes is for those genes which are under selection pressure to distort the sex ratio in the favour of the gene (because the gene is only passed on if it is in an organism of a particular sex). ${ }^{\text {vii }}$ Such entities (genes, say) are not necessarily parts of organisms which are of the same species. Since the same gene can occur in organisms of different species, and since cross-species gene transfer has been widely documented, a biological population of genes need not occur within organisms of the same species.

For an example of entities which form supra-species biological populations, consider lichens, which are symbiotic organisms formed by a fungi together with green algae or cyanobacteria. Some lichens reproduce asexually by emitting diaspores, in which the reproductive structures (soredia) are fungal hyphae wrapped around the algae or cyanobacteria. But many lichens are also sexual perverts: the fungi can generate fungal spores which must be 'impregnated' by algae in order to generate a new lichen (Honegger and Scherrer [2008]). Thus when lichen engage in either sexual or asexual reproduction, the lichen itself is the reproductive unit (though the algae in some lichen may also reproduce independently). ${ }^{\text {viii }}$ And since a group of lichen can vary with respect to their fitness, and such fitness can be heritable, a group of lichen can undergo population dynamics without satisfying $S$.

\subsection{Against $P$}


Two organisms can be in the same biological population but be separated by huge distances (think of penguins, geese, blue whales, or humans). What defenders of $P$ must mean when they require populations to be constrained within 'a more or less well defined geographic region' (Futuyma) or 'the same spatial area' (Millstein) is that members of a population must be confined to a species-appropriate geographical region. This geographical constraint might be different in magnitude for, say, E. coli compared with blue whales. However, I doubt that there is such a geographical constraint on biological populations independent of geographical constraints on species. Perhaps different populations of finches are each confined to their own island in the Galapagos, but such geographical isolation supervenes on each species of finch being confined to their own island. Perhaps populations of Joshua trees are confined to the Mojave desert, but that is only because Yucca brevifolia is confined to the Mojave desert.

One problem with $P$ is its vagueness. How proximal must two organisms be such that they satisfy $P$ ? Within the boundaries of the solar system? On the same continent? As suggested above, the answer will depend on facts regarding the mobility of the species in question. Two bacteria may have to be in the same Petri dish; two whales may have to be in the same ocean. But if a bacterium travels a great distance on the back of a penguin, there is no telling how distal its potential population partners may be. Moreover, such distances may be modified by contingent ecological events or technological developments (some potential members of my population are at this moment in outer space). 
Requiring a population to be confined to a well-defined geographic region may be relevant in ecological contexts, but with respect to the concept of 'biological population' (that is, the context of evolutionary biology), perhaps at best the motive for requiring $P$ is to ensure that $C$ is satisfied. If two groups of organisms are separated by an insurmountable geographic distance or some other barrier, then the two groups might not share causal relations. Thus, if one thought that $C$ is a necessary condition, one will think that $P$ (construed very broadly) is a necessary condition. I investigate $C$ in $\S 4$. Regardless of one's view regarding $C$, however, if $P$ is indeed a compelling condition only insofar as it is a necessary condition for $C$, then $P$ is itself not an independent requirement for populations.

\subsection{Against T}

A group of organisms need not be organized into types for evolution to occur or for evolutionary descriptions or explanations to be coherent. The countervailing position is based on the fact that descriptions of population dynamics are often formulated as the change of frequencies of discrete traits or organism types over time; if there are no types, then there can be no frequencies, and so no change of frequencies (Dawkins [1982]). But as (Godfrey-Smith [2009]) notes, descriptions of population dynamics can be based on orderings and metrics rather than types. His example is height. Population dynamics can be characterized by employing ordinal measures (e.g., 'taller than') or cardinal measures (e.g., ' 185 centimetres'), and not necessarily nominal groupings (e.g., 'tall type'). ix $^{\text {ix }}$ 


\section{Causal Connectivity}

Condition $C$-the requirement that two individuals must be related by causal connections if they are to be in the same biological population - is highly abstract. Here I note several difficulties associated with requiring $C$ as a condition for biological populations. I will use this notation: if two entities (A and B) are related by a causal connection that satisfies $C$, I note this as $\mathrm{A}^{\wedge} \mathrm{B}^{\mathrm{x}}{ }^{\mathrm{A}} \mathrm{A}$ is directly related by $\wedge$ to $\mathrm{B}$ if and only if $\mathrm{A}^{\wedge} \mathrm{B}$, and $\mathrm{A}$ is indirectly related by $\wedge^{\wedge}$ to $\mathrm{N}$ if and only if $\mathrm{A}^{\wedge} \mathrm{B}$, $\mathrm{B}^{\wedge} \mathrm{C}, \mathrm{C}^{\wedge} \mathrm{D} \ldots \mathrm{M}^{\wedge} \mathrm{N}$ and not $\mathrm{A}^{\wedge} \mathrm{N}$. To require $C$ as a condition for the composition of a biological population from a grouping of individuals is to say that entities are part of the same biological population only if (i) all the individuals are related directly by ${ }^{\wedge}$, or (ii) all the individuals are related either directly or indirectly by $\wedge^{\wedge}$. Figure $1 \mathrm{a}$ graphically depicts the satisfaction of (i) by five individuals (A-E), and Figure1b graphically depicts one possible way in which (ii) could be satisfied.

Suppose by $C$ we mean (i). Then a grouping of individuals can be tightly connected by $\wedge$ but if (i) is not satisfied for all pairs of individuals then the grouping of individuals would necessarily be construed as fragmented into several distinct biological populations. Figure 1c graphically depicts such a possibility. This has the odd consequence that individuals can form a grouping which satisfies $V, F$, and $H$, and can interact in a complex web of fitness-affecting causal relations, including reproductive relations which constitute the satisfaction of $V, F$, and $H$, and yet not be 
considered a unified biological population. Instead, such a grouping would be defined as several biological populations with overlapping membership. In Figure $1 \mathrm{c}$, the pairs of individuals that are directly related are $\mathrm{A}^{\wedge} \mathrm{B}, \mathrm{A}^{\wedge} \mathrm{C}, \mathrm{B}^{\wedge} \mathrm{C}, \mathrm{A}^{\wedge} \mathrm{D}, \mathrm{A}^{\wedge} \mathrm{C}$, $\mathrm{D}^{\wedge} \mathrm{C}, \mathrm{C}^{\wedge} \mathrm{E}$, which, according to (i), forms three populations (1: A-B-C; 2: A-D-C; 3: D-E), with individuals A, C, and D each in two populations. This suggests that (i) is too strong a requirement.

Suppose by $C$ we mean (ii). Then a grouping of individuals only need be pairwise related by $\wedge^{\wedge}$ to be part of the same biological population. We know, however, that there are biological cases in which two sub-groups of individuals are related indirectly by ${ }^{\wedge}$ to each other and yet are not part of the same biological population. Ring species exemplify such a structure $\left(\mathrm{A}^{\wedge} \mathrm{B}, \mathrm{B}^{\wedge} \mathrm{C}, \mathrm{C}^{\wedge} \mathrm{D}\right.$, but not $\left.A^{\wedge} D\right){ }^{x i}$ Figure $1 d$ graphically depicts this scenario. The Greenish warblers (Phylloscopus trochiloides), for instance, exist as two distinct types in the Himalayan region: viridanus and plumbeitarsus. The two types do not interbreed and have certain distinctive traits (song, plumage, and genetics), though their body shapes, body sizes, and ecological habitats are similar, and the two types are linked by reproductive relations via a series of inter-breeding warblers between which there are no distinct population boundaries. ${ }^{\text {xii }}$ Among evolutionary biologists it is controversial whether the two tails of a ring species should be considered distinct species, but there is widespread consensus that a ring species structure exemplifies the process of speciation: the two tails of a ring species do not co-evolve, and there is selection against hybrids between subsections of a ring. .iii $^{\text {The viridanus and plumbeitarsus }}$ 
warblers satisfy (ii), but they are not part of the same biological population. This suggests that (ii) is too weak a requirement.

\section{[insert figures 1a-d]}

Since causal interactions that unite individuals into a biological population can occur at different times, another difficulty that an approach that relies on $C$ faces is specifying the temporal constraints on the occurrence of causal interactions. The most constraining temporal requirement on $C$ would be that individuals are part of the same population only if they are presently causally connected. This, though, would be absurd, since the relevant causes can be extremely transient. During one moment a fly might be part of a population and during the next moment it might not. The most liberal temporal requirement on $C$ would be that individuals are part of the same population only if they are causally connected sometime. This raises an epistemic demand that seems impossible to meet: if two individuals ever, over the duration of their existence, have a sufficient causal interaction, then they count as members of a biological population. Indeed, if the offspring of two individuals interact in just the right way, and the connectivity requirement is (ii) from above, then those two individuals are part of the same biological population. Thus, in order to determine if multiple organisms are part of the same biological population a biologist would have to know a complete account of the causal relations of the organisms (and their offspring), past, present, and future. 
We should not attempt to find some explication of $C$ that is weaker than (i) but stronger than (ii) above, nor should we attempt to determine the temporal constraint (between presently and sometime) in which $C$ must be satisfied in order for two individuals to be part of the same population. I hope to have indicated the difficulty of such tasks. Moreover, there is reason to think that $C$, as stated in abstract terms, is not necessary for a grouping of individuals to undergo dynamics. Consider a species comprised of two phenotypically distinct types, Big (B) and Little (L), which reproduce asexually. In a particular environment $(\mathrm{E}), \mathrm{B}$ individuals have a much greater ability to survive than L individuals, due to the phenotypic difference between the two types with respect to E. But suppose there is no causal interaction between $\mathrm{B}$ individuals and $\mathrm{L}$ individuals, and nor are there causal interactions between individuals of a given type. Nevertheless, the set of all B and L individuals satisfies $V, F$, and $H$, because there are differences in fitness among the individuals, and the difference-maker is heritable. This group of individuals undergoes population dynamics with no causal interactions between the individuals. ${ }^{\text {xiv }}$

A defender of $C$ could respond in several ways to such examples. One would be to add a third kind of relation that could constitute $C$, in addition to the 'direct' and 'indirect' relations discussed above: namely, that two individuals can satisfy $C$ if they are related common-causally. Using the notation from above, two entities (A and B) are common-causally related to each other by another entity $\mathrm{N}$ via the ${ }^{\wedge}$ relation if and only if $\mathrm{N}^{\wedge} \mathrm{A}$ and $\mathrm{N}^{\wedge} \mathrm{B}$. This would resolve the above case because token elements $i$ of $E, B$, and $L$ are related common-causally: $E_{i} \wedge A_{i}$ and $E_{i}{ }^{\wedge} B_{i}{ }^{x v}$ The 
grouping of $\mathrm{B}$ and $\mathrm{L}$ individuals undergoes population dynamics, and the grouping also satisfies $C$ (common causally), and thus the example is not a challenge to the necessity of $C$. My view is that this stretches the notion of causal interaction beyond recognition. A defender of $C$ has a better response to examples like the one above. The very concept of interest is the notion of a co-evolving grouping of individuals. The B type and the L type, on an evolutionary time-scale, do not necessarily share the same evolutionary fate. Consider, as an analogy, the game in which people take turns adding sentences to a developing story. If the players all add sentences to a single developing story, the final product will be a more-or-less coherent narrative, but if the players separate into two non-interacting groups and develop two parallel but independent stories, then the two resulting stories will very likely have little in common. It may be true that the joint grouping of B and L organisms undergoes population dynamics without satisfying $C$, but the group of B organisms does not necessarily share the same evolutionary fate as the group of L organisms (B organisms might have one fate and $\mathrm{L}$ organisms another). ${ }^{\mathrm{xvi}}$ For individuals of type $\mathrm{B}$ and individuals of type $\mathrm{L}$ to be part of the same biological population they would have to be in groupings that share the same evolutionary fate, and for that they would somehow have to satisfy $C$. Many hold that reproduction is the glue that binds two individuals to the same evolutionary fate; others hold that shared genetic material is the glue, and still others deny this; see, for example, (Barker [2007]). Whatever is the glue, $C$ is necessary. ${ }^{\text {xvi }}$ 
In their discussion of 'integrative cohesion' of species, Barker and Wilson [(2010)] note how 'gappy' species can be-species are typically separated into multiple diffused sub-populations separated by many different kinds of barriers (geographic, behavioral, etc.). This implies that members of a species are not necessarily (indeed, not typically) causally related, even indirectly (using the terminology from above). So $C$ is not necessary for species membership. But from this Barker and Wilson rightly do not draw the implication that $C$ is not necessary for membership in a biological population. All members of the same species are not necessarily all members of the same biological population. Members of the same species separated by a large gap (for example) may not share the same evolutionary fate. $^{\text {xiii }}$

For reasons described above, though, little can be said about the tightness or directness or the temporal span of the necessary causal relations that constitute $C$. We should dispel with thinking of $C$ in such abstract terms; that is, we should dispel with the requirement that two individuals be causally connected simpliciter in order for them to be part of the same biological population. Instead, we should construe $C$ in more specific causal terms.

To use a notion from (Cartwright [2007]), my suggestion is to think of the causes that relate individuals as 'thick causal concepts.' These are specific, finegrained relations that influence fitness - A is more able to reach the low-hanging fruit than B; C mates with D; E eats F. There are a great plurality of such causal relations and they can (and should) be construed at as fine a grain as possible, 
because more abstract causal relations are constituted by multiple more specific relations, and both the abstract and specific relations can trade-off against each other with respect to determining whether or not two individuals satisfy $C$. Individuals have many types of fitness-affecting relations with other individuals, and many tokens of these types, and some types (and tokens) of these fitness-affecting relations might be manifest by two individuals while other types (and tokens) of these fitnessaffecting relations might not manifest. Suppose, for example, that types of fitnessaffecting relations include those related to resource access, those related to predator avoidance, and those related to reproduction. Each of these types of relations has myriad sub-types (an organism can avoid predation by hiding better, tasting bitter, smelling badder...). Each of these sub-types has uncountably many tokens (individual $x$ ran faster than $y$, who ran faster than $z \ldots$..). Such tokens can trade-off against each other ( $x$ ran faster than $y$, but $y$ was better at hiding than $x$ ). Not all of these fitness-affecting relations are straightforwardly causal, of course (e.g. 'faster than', 'taller than'), but at least some are. The uncountably many types, sub-types, and tokens of fitness-affecting causal relations mean that $C$ is an abstraction from great complexity. Construing $C$ in fine-grained terms allows one to keep track of such complexity, at least conceptually.

Which types of causes influence fitness and so help to define biological populations? Conceptually, a compelling answer would appeal to a subset of fitnessaffecting causes, rather than all fitness-affecting causes, because an organism's fitness can be affected by causes that originate from entities which should not be 
treated as part of the same population, such as drift-like events (a thunderstorm which generates lighting which then kills a cedar tree is not thereby part of the same population as the cedar tree). ${ }^{\mathrm{xix}}$

However, specifying more precisely the causes that matter to grouping organisms is, I think, impossible. In the words of Travis and Reznick: 'A wide variety of ecological forces create differences in mortality rates or levels of reproductive success among individuals' ([2009] pp. 110). Indeed, there are uncountably many fine-grained types of causes that influence fitness, and many of these causes can be manifest to varying degrees. Thus I agree with Lewens when he writes that "we should not expect any good principled answer to the question of which elements of some evolutionary process should count among contributors to fitness' ([2010] pp. 314).

Methodologically, moreover, appealing to fitness-affecting causes to determine membership in a biological population is hopeless. This is for two reasons. First, given the many relevant causes which could constitute $C$, and given that these causal relations can be widely dispersed in space and time, determining whether or not a group of individuals is related by the necessary causal relations would be epistemically difficult. Second, some research programmes in evolutionary biology are directed at determining exactly what the fitness-affecting causes are for a group of organisms, so the requirement that researchers group organisms by fitnessaffecting causal relations would be epistemically impossible.$^{\mathrm{xx}}$ 
In short, for groups of individuals to share the same evolutionary fate on an evolutionary time-scale they must satisfy $C$. But $C$ is laden with numerous conceptual and epistemic difficulties.

\section{Massively Multidimensional Population Constructs}

Despite the challenges associated with defining a biological population in terms of causal interactions, some might maintain a commitment to $C$ on the grounds that the abstract classical requirements of biological populations require individuals to causally interact, if those individuals are to have a robust shared evolutionary fate. In $\S 4$ I suggested that we should construe the causal interactions that constitute $C$ at a fine grain. Individuals in a biological population are related to each other by specific causal interactions which affect reproduction and survival, which are manifold in kind, and which manifest to varying degrees. Relations between organisms can be conceived of as a massively multidimensional construct, in which the dimensions are the many fine-grained fitness-affecting causal relations. Since most of these causal relations are manifested to varying degrees, we can represent the causal relations between individuals by a multidimensional map, in which a measure on a particular dimension represents the degree to which an individual is related to others by a particular causal relation. ${ }^{\mathrm{xxi}}$ To think that one can circumscribe a population based on causal relations between individuals is to assume that a particular topography on this multidimensional map is definitive of a population. 
To make this idea more precise, let me introduce a piece of terminology. A 'causal profile' for an individual is a measure of the intensity of the various finegrained causal relations between this individual and other individuals (averaged over each other individual). Suppose our causal relations of interest are, say, $\alpha, \beta$, and $\gamma^{\text {xxii }}$ We can construct a three-dimensional graph in which each axis measures the average intensity of $\alpha, \beta$, and $\gamma$ between a particular individual and other individuals. ${ }^{\text {xiii }}$ A causal profile of a particular individual is a point on this graph. The topographical space that circumscribes a population is, then, a delimitation of causal profiles: individuals whose causal profiles are within the topographical boundary are part of the same population, and vice versa, if an individual's causal profile is outside the topographical boundary, then that individual is not part of the population. I graphically depict this in Figure 2a.

All the difficulties regarding abstract $C$ discussed in $§ 4$ apply to delimiting populations based on causal profiles. To determine the value of a causal profile ought we take into account only direct causal relations, or direct and indirect causal relations? Over what temporal span ought the values of the relations depend? Suppose these difficulties had compelling solutions. Two new problems arise.

First, an obvious problem for this approach is why one topography rather than another is constitutive of a population. To stipulate one topography is to apply a particular weighting scheme to the relevant fine-grained causal relations (where a weighting scheme is an assessment of the relative importance of the various causal relations vis-à-vis their influence on fitness). Another weighting scheme that differs 
from the first in entirely arbitrary respects could generate a different topography and so define population membership differently. The two topographies could both be equally reasonable yet differ from each other in entirely arbitrary respects. The extent to which some particular causal relation happened to influence fitness in the past is merely an empirical question, but if one wants to delimit a biological population in the present, one is limited by the fact that one typically does not know the extent to which some particular causal relation has influenced fitness (indeed, it is often this very question that is being addressed by delimiting a biological population). Of course the past can be a valuable guide to judging the extent to which some particular causal relation influences fitness, but the great complexity of the biological world does not afford simple extrapolation on such questions. Salamanders change colour to blend in with their environment and thereby avoid predators, while flamingos change colour to stand out in their environment and thereby attract mates.

In Figure 2b I graphically depict two topographies applied to the same individuals. The two topographies overlap, but they disagree about population membership at the edges. The two individuals with causal profiles $\mathrm{B}$ and $\mathrm{C}$ belong to the same population according to one topography but belong to different populations according to the other topography.

In terms of this spatial device, population pluralism holds that there is a range of admissible topographies in a space of causal profiles that can define a biological population. There are, presumably, topographies that are inadmissible on theoretical 
grounds. For example, any topography which includes only causal profiles that have a null value for causal relations that we deem necessary (such as reproductive relations, say) would be inadmissible (such topographies might fail the "shared evolutionary fate' condition, for instance). This spatial device is not meant to replace the more abstract conditions $H, V$, and $F$, but rather is meant to supplement $C$, and so if one held $H, V$, and $F$ as necessary conditions for a biological population, and a topography contained only individuals that as a group did not satisfy all of $H, V$, and $F$, then that topography would be inadmissible. In short, not all topographies in the space of causal profiles are admissible. ${ }^{\text {xxiv }}$ But there are a plurality of admissible topographies. There is no unique way to carve the space of fitness-affecting causal relations in order to delineate biological populations.

Second, the sharp boundaries of the 'population spaces' represented in Figures $2 \mathrm{a}$ and $2 \mathrm{~b}$ are misleading. The boundaries give the impression that, had an individual that was not in a certain population had slightly different causal relations to other individuals, and this difference pushed its causal profile from just outside the population delimiting boundary to just inside it, then that individual would be in the given population. Similarly, since the topographical boundaries are meant to delimit the grouping of individuals which jointly evolve, the sharpness of the boundaries suggests that all organisms with causal profiles inside the boundary share this important property (evolving together) to the same degree, while all organisms with causal profiles outside the boundary lack this property. But as (Gannett [2003]) and others argue, boundaries of causal interactions in evolutionary contexts are 
imperfect. Barriers to gene exchange, for example, are incomplete and fluid. Individuals can be more or less part of the same biological population. ${ }^{\mathrm{xxv}} \mathrm{A}$ better representation would be sensitive to the varying causal embeddedness of individuals and would avoid arbitrary boundaries between two individuals with similar causal profiles. Figure $2 \mathrm{c}$ is an attempt to graphically depict a group of individuals in such a way. Figures $2 \mathrm{~b}$ and $2 \mathrm{c}$ are visual representations of population pluralism.

\section{[insert figures 2a -2c]}

Population pluralism can be characterized as the negation of two distinct theses. The first is population uniqueness (there is a unique topography in the space of causal profiles which represents a biological population). The second is population sharpness (there is a sharp boundary in the space of causal profiles which delineates those individuals which are part of the same biological population from those which are not). Population pluralism denies both population uniqueness and population sharpness.

That population sharpness is false is conceded by some who hold a narrow interpretation of 'biological population'. For instance, Millstein agrees that 'populations are blurry entities, with edges that are not always well defined [sic]' ([2010] pp. 80). The more controversial thesis is population uniqueness. Those who write about biological populations often refer singularly to the biological population when discussing a circumscribed grouping of individuals. I noted in $\S 2$, as an 
example, (Millstein [2010]), who claims that causal interactions among individuals generate a 'biological whole'. Similarly, (Millstein [2009]) claims that populations are 'individuals' - integrated, cohesive, spatiotemporally localized entities. Moreover, in $§ 6$ I show that positions in two recent debates in theoretical biology depend on population uniqueness; for example, (Otsuka et al. [2011]) and (Gildenhuys [forthcoming]) assume that groups of organisms constitute unique biological populations, fixed by particular facts about the organisms and their environment. In terms of the spatial device, population uniqueness holds that, given a space of causal profiles, there is only one topography that can accurately represent a biological population. Since a space of causal profiles represents the relevant causal relations between individuals, adding or subtracting axes would require a different but nevertheless unique topography to delimit a biological population, according to population uniqueness.

Let me reiterate the problems that I have raised for population uniqueness, putting them in terms of the spatial device. First, determining the axes of the space in the first place is enormously difficult, and different sets of axes entail different population-delimiting topologies. Second, determining a location in the space for any given individual requires computing the strength of causal interactions between that individual and other individuals, and to do this one must settle the question of requiring either a direct or an indirect connection, or something in between (using the terminology in $\S 4$ ), and one must settle the question of what is the appropriate temporal span over which the relations are assessed, and then one must actually 
determine the strength of all of these causal relations. These problems, one might say, are mere technicalities. The third problem with population uniqueness is conceptual. Once one has determined the axes and the location of each point in the space, one must demarcate part of the space with a topology which represents a biological population. But why this topography? A slightly different assessment of the significance of the relevant causal relations would adjust the scaling of each axis with respect to the other axes, and would thus require an alternative but equally valid topography. Among the theoretically admissible topographies, there is no theoretical basis for preferring a particular topography. At the very least, I have raised challenges for thinking otherwise.

It would not help to stipulate a single topography as representing a biological population based on the fact that the circumscribed individuals influence each other's fitness, since, again, for those individuals there would be other equally valid topographies such that the individuals influence each other's fitness. Similarly, it would not help to stipulate the single largest topography as representing a biological population, since there could be other equally valid and equally large topographies.

In terms of the spatial device, population pluralism holds that there are multiple equally valid topologies. The problems I have raised for population uniqueness are not merely artifacts of the spatial representation of $C$; rather, the spatial representation is a helpful way of exposing the problems of population uniqueness and motivating population pluralism. 


\section{Population Uniqueness and Natural Selection}

I have argued against population uniqueness. However, positions in several contemporary debates in theoretical biology depend on population uniqueness. Population pluralism renders these positions dubious.

\subsection{Statisticalism and its Discontents}

A recent interpretation of evolutionary theory holds that natural selection is a statistical summary of individual-level events, rather than a cause or force of population change. ${ }^{\mathrm{xxvi}}$ A criticism raised by (Otsuka et al. [2011]) and (Gildenhuys [forthcoming]) against a novel argument for the statistical interpretation due to (Walsh [2010]) assumes population uniqueness.

The novel argument presented in (Walsh [2010]), drawing on (Gillespie [1974], [1975]), begins by noting that in populations that have constant size and withingeneration variation in reproductive output, the fitness of a trait $i$ can be estimated by:

$$
w_{i}=\mu_{i}-\sigma_{i}^{2} / n
$$

where $\mu_{i}$ is the mean reproductive output of $i, \sigma_{\mathrm{i}}^{2}$ is the variance in reproductive output of $i$, and $n$ is population size. Walsh considers the following model:

Trait 1: $\mu_{1}=0.99, \sigma_{2}^{2}=0.2$

Trait 2: $\mu_{2}=1.01, \sigma_{2}^{2}=0.4$ 
Walsh's great insight was to show the following. In a population of 84 individuals sub-divided into 14 populations of six individuals each and between which the distribution of Traits 1 and 2 are homogeneous, then for all sub-populations $k$ the fitness of Trait 1 is greater than the fitness of Trait 2 :

$$
w_{1, k}>w_{2, k}
$$

However, in the overall population, the fitness of Trait 1 is less than the fitness of Trait 2:

$$
w_{1}<w_{2}
$$

Walsh notes the affinity of this result with Simpson's paradox. This is an argument for the statistical interpretation of evolutionary theory because if one interprets fitness in causal terms, then one must hold both that (i) fitness causes a relative increase of Trait 1 over Trait 2 in every sub-population, and (ii) fitness causes a relative increase of Trait 2 over Trait 1 in the population as a whole. According to Walsh, (i), (ii), and a basic principle of causality — namely, the 'Sure Thing Principle' associated with (Pearl [2000]) — are an inconsistent triad. Solution? Abandon the causal interpretation of fitness.

In response, (Otsuka et al. [2011]) claim that 'Walsh's argument presupposes that the means by which we define and partition a biological population is nothing more than a matter of our descriptive interests.' In contrast, according to Otsuka et al., the population size $n$ in Gillespie's model is held constant by a density-regulating process, which ... usually depends on environmental factors, such as habitat condition, abundance 
and quality of foods, number of predators, and so on. Clearly, then, what determines population size $n$ is not our subjective interest but an objective property of the environment surrounding organisms. ([2011] pp. 212)

Otsuka et al. claim that such a density-regulating process warrants considering a particular individual as part of one population only. Walsh's argument against the causal interpretation of fitness is compelling - goes this response - only given his 'illegitimate assumption that biological populations can be demarcated arbitrarily' ([2011] pp. 212). However, Walsh's argument does not assume that one can arbitrarily demarcate biological populations, but only that there is a plurality of possible ways to demarcate biological populations. And this is precisely what I defended in $§ 5$.

Also commenting on Walsh's argument, (Gildenhuys [forthcoming]) argues that there can be only one effective population size 'for any system governed by population genetics, provided the theory is not a failed one.' Gildenhuys claims that there is an 'array of facts about a population that determine its effective size.' However, as I have already argued, thin causal notions like 'density regulating process' (akin to 'causal interaction') and 'facts about a population' ought to be construed at a fine-grain. Different micro-level causes and other facts about populations that constitute density-regulating processes relate organisms in myriad ways. ${ }^{\text {xxvii }}$ To claim that there is 'an objective property of the environment surrounding organisms' (as Otsuka et al. put it) that serves to delimit biological 
populations is to suppose that there is a unique topography of causal profiles that constitutes a population. Both (Otsuka et al. [2011]) and (Gildenhuys [forthcoming]) presuppose population uniqueness in their criticisms of Walsh's argument against the causal interpretation of fitness. This presupposition is at odds with the population pluralism I defended in §5. Thus the argument presented in (Walsh [2010]) remains a compelling challenge to the causal interpretation of fitness.

\subsection{Price at What Price?}

The Price equation has been interpreted as a quantitative measure of evolutionary change due to individual-level and group-level selection. Here is one form of the Price equation:

$$
w \Delta z=\operatorname{Cov}(W, Z)+E\left(\operatorname{Cov}_{k}(w, z)\right)
$$

The first term on the right hand side, $\operatorname{Cov}(W, Z)$, represents the covariance of group phenotype $(Z)$ and group fitness $(W)$, and the second term on the right hand side, $E\left(\operatorname{Cov}_{k}(w, z)\right)$, represents the average covariance of individual phenotype $(z)$ and individual fitness $(w) .{ }^{\text {xxvii }}$ The former is interpreted to measure group-level selection and the latter is meant to measure individual-level selection.

(Okasha [2006]) criticized the Price approach to multi-level selection because of its difficulty accounting for 'cross-level byproducts'. The following case is presented by (Sober [2011]) to illustrate the problem of cross-level byproducts: 
Consider two zebra herds; all the zebra in the first herd run fast and all those in the second run slow. Suppose that lions randomly select a zebra to attack, but that a zebra under attack has a better chance of escaping if it runs fast. Suppose further that a zebra's fitness is unaffected by what the other zebras in its herd are like. In this case, the intuitive conclusion is that there is purely individual selection. True, running fast is good for the herd, in that fast herds are less likely to be hunted to extinction than slow ones; however, the trait does not evolve because it is good for the herd. If the two herds are distinct groups, this example shows that group selection cannot be defined as fitness variation between groups. ([2011] pp. 225)

Such a case is a challenge to the Price approach, according to Okasha, because all the variance in fitness is between the zebra herds, rather than within the herds, and so according to the Price approach selection is at the group level, yet intuitively all the selection is at the individual level. ${ }^{\mathrm{xxix}}$

Sober's rejoinder to the problem of cross-level byproducts is to appeal to an 'interactionist definition of group', in which multiple organisms comprise a group relative to a particular trait $\mathrm{T}$ 'precisely when their trait values for $\mathrm{T}$ affect each other's fitness.' In the above case, the zebras do not constitute distinct groups with respect to running speed, according to this definition of group. If there are no distinct groups, there can be no group-level selection. Thus the Price approach is brought into line with the intuition that the case involves only individual-level selection, 
despite the fact that all the variance in fitness is between the zebra herds rather than within the herds.

Two organisms can satisfy the condition for membership in an 'interactionist group' (their respective values for some particular trait influence their respective fitness) and yet not satisfy any of the conditions for membership in a biological population. For instance, if I were wandering in the savannah with the zebras, the zebras' running speeds relative to my running speed would influence my fitness during a lion attack, and so according to Sober's account I would be in the same group as the zebras relative to running speed, but intuitively I would not be in the same biological population as the zebras. We lack the 'glue' discussed in $§ 4$ (reproductive relations, or exchanged genetic material, or...). In terms of the spatial device in $§ 5$, I have a null value on an axis for which any admissible topography should have at least some positive value, according to even the very broadest interpretations of biological populations.

Perhaps such glue is implicit in the notion of an interactionist group. Such a constraint must be assumed in the context in which the Price equation is meant to apply, since, after all, the Price equation is intended to provide a (supposedly causal) decomposition of multi-level selection into individual-level and group-level selection, and biological populations are precisely those groupings of individuals which jointly evolve by natural selection. An interactionist group is a special subset of a biological population, one in which the individuals' values for some trait affect each other's fitness. Sober's rejoinder requires that there be a unique interactionist 
group (in the zebra case, there must be one and only one group, to bar the possibility of group-level selection). However, the thesis of population pluralism defended above holds that for a group of individuals there is no unique biological population; rather, there are a plurality of admissible biological populations. Each admissible biological population might have, as a subset, an interactionist group. In terms of the spatial device employed in $\S 5$, each admissible topography might have a subtopography which represents the individuals that constitute an interactionist group, and since there are multiple admissible topographies, in principle there are multiple admissible interactionist groups. In short, Sober's attempt to save the Price approach from Okasha's critique rests on an assumption, population uniqueness, which is at odds with the population pluralism argued for in $\S 5$.

\section{Conclusion}

I have defended a radical account of the notion of 'biological population'. Population pluralism holds that there are many ways that a group of individuals can be related such that the group satisfies the conditions necessary for that group to undergo population dynamics. Narrow interpretations of 'biological population', such as that of Millstein and Futuyma, are based on conditions like $S$ and $P$ which are open to numerous empirical and conceptual counterexamples, or based on condition $C$ which 
faces numerous conceptual difficulties. Finally, population pluralism renders less compelling certain positions in other disputes in theoretical biology.

To conclude, I want to briefly compare population pluralism to seemingly similar positions. Population pluralism is consistent with the 'promiscuous realism' prominently advanced by Dupré, but is in one sense more radical. Here is a succinct description of Dupré's promiscuous realism: 'The point, once again, is not that there are no real divisions in nature between kinds of things, divisions that are appropriate for a particular kind of enquiry, but that what those divisions are will depend on what the enquiry is' ([2006] pp. 116). Population pluralism is consistent with the view that population divisions depend in part on what the subject of the domain of enquiry is (systematics, population dynamics, genetics, ecology, etc.). However, population pluralism further maintains that even given a particular domain of enquiryevolutionary dynamics - there are no unique divisions in nature appropriate to the domain. Promiscuous realism maintains that there are different ways to appropriately demarcate individuals into groups between domains of enquiry, and population pluralism maintains the even more radical view that there are different ways to appropriately demarcate individuals into groups within a single domain of enquiry (namely evolutionary biology).

Similarly, population pluralism is consistent with species pluralism, associated with (Kitcher [1984]) and others, but is, again, in a sense more radical. To be clear, population pluralism and species pluralism are about different subjects altogether, given the arguments I noted in $\S 3$ (biological populations are not species, and nor do 
they require conspecificity). But the two positions are worth comparing. Kitcher's version of species pluralism allows an organism to be considered a member of different species according to different species concepts - this is pluralism only given plural concepts. The population pluralism defended here allows an organism to be considered a member of different biological populations according to the same population concept (namely, an evolving group of organisms).

This is a radically broad interpretation of what counts as an evolving group of organisms. From a theoretical perspective, there are a great number of ways for individuals to be delimited as a grouping such that the grouping can undergo population dynamics. The most compelling candidate condition to constrain broad interpretations of the concept of 'biological population' - causal connectivity - in fact warrants population pluralism.

\section{Contact Information}

Jacob Stegenga

Department of Philosophy

University of Utah

215 South Central Campus Drive

Carolyn Tanner Irish Humanities Building, 4th Floor

Salt Lake City, Utah

USA 84112 
jacob.stegenga@utah.edu

http://individual.utoronto.ca/jstegenga

\section{Acknowledgements}

I am grateful to members of the University of Toronto Philosophy of Biology Research Group, and specifically to Denis Walsh and Eugene Earnshaw, for fruitful discussion of this paper. Alex Marcellesi, Ciprian Jeler, Matt Barker, and Thomas Reydon gave detailed comments on drafts. I am especially grateful to Jennifer King (www.jenniferkingcreative.com) for designing the graphical elements. Financial support was provided by the Banting Postdoctoral Fellowships Program administered by the Social Sciences and Humanities Research Council of Canada.

\section{References}

Alexandrino, J., Baird, J. E., Lawson, L., Macey, J. R., Mortitz, C. and Wake, D. B. [2005]: 'Strong Selection Against Hybrids at a Hybrid Zone in the Ensatina Ring Species Complex and its Evolutionary Implications', Evolution, 59 (6), pp. $1334-7$.

Bapteste, E., Bouchard, F. and Burian, R. [2012]: 'Philosophy and Evolution: Minding the Gap between Evolutionary Patterns and Tree-like Patters' in 
Anisimova (ed), Evolutionary Genomics: Statistical and Computational Methods, Springer.

Barker, M. [2007]: 'The Empirical Inadequacy of Species Cohesion by Gene Flow', Philosophy of Science, 74, pp. 654-665.

Barker, M. and Velasco, J. [forthcoming]: 'Deep Conventionalism about Evolutionary Groups', Philosophy of Science.

Barker, M. and Wilson, R. [2010]: 'Cohesion, Gene Flow, and the Nature of Species', Journal of Philosophy, 107 (2), pp. 59-77.

Baum, D. [2009]: 'Species as Ranked Taxa', Systematic Biology, 58, pp. 74-86.

Burt, A. and Trivers, R. [2005]: Genes in Conflict: the Biology of Selfish Genetic Elements, Cambridge: Harvard University Press.

Cartwright, N. [1979]: 'Causal Laws and Effective Strategies', Nous 13, pp. 419437.

Cartwright, N. [1983]: How the Laws of Physics Lie, Oxford University Press.

Cartwright, N. [1999]: The Dappled World: A Study of the Boundaries of Science, Cambridge University Press.

Cartwright, N. [2007]: Hunting Causes and Using Them, Cambridge University Press.

Dawkins, R. [1976]: The Selfish Gene, Oxford: Oxford University Press. 
Dawkins, R. [1982]: The Extended Phenotype: The Gene as the Unit of Selection. Oxford: Oxford University Press.

de Queiroz, K. [1999]: 'The General Lineage Concept of Species and the Defining Properties of the Species Category', in Wilson (ed.), Species: New Interdisciplinary Essays, Bradford Books.

Dupré, J. [1993]: The Disorder of Things: Metaphysical Foundation of the Disunity of Science, Harvard University Press.

Dupré, J. [2006]: Humans and Other Animals, Oxford University Press.

Dupré, J. [2010]: ‘The Polygenic Organism', Sociological Review, 58 (Suppl 1), pp. 19-31.

Dupré, J. [2012]: Processes of Life, Oxford University Press.

Earnshaw, E. [2012]: Modeling Evolution, Ph.D. Dissertation, University of Toronto.

Ereshefsky, M. [1998]: ‘Species Pluralism and Anti-Realism', Philosophy of Science, 65, pp. 103-120.

Futuyma, D. J. [1986]: Evolutionary Biology, Sinauer Associates, Inc., Sunderland. Gannett, L. [2003]: 'Making Populations: Bounding Genes in Space and in Time', Philosophy of Science, 70, pp. 989-1001.

Gildenhuys, P. [forthcoming]: 'Arbitrariness and Causation in Classical Population Genetics', British Journal for the Philosophy of Science. 
Gillespie, J. [1975]: 'Natural Selection for Within-Generation Variance in Offspring Number II', Genetics, 81, pp. 403-413.

Gillespie, J. [1974]: 'Natural Selection for Within-Generation Variance in Offspring Number', Genetics, 76, pp. 601-606.

Godfrey-Smith, P. [2009]: Darwinian Populations and Natural Selection, Oxford University Press.

Honegger, R. and Scherrer, S. [2008]: 'Sexual reproduction in lichen-forming ascomycetes', in Nash (ed.), Lichen Biology, Cambridge University Press.

Hull, D. [1980]: 'Individuality and Selection', Annual Review of Ecology and Systematics, 11, pp. 311-332.

Irwin, D. E., Bensch, S. and Price, T. [2001]: 'Speciation in a Ring', Nature, 409, pp. 333-337.

Irwin, D. E. [2000]: ‘Song Variation in an Avian Ring Species’, Evolution, 54 (3), pp. 998-1010.

Keeton, W. and Gould, J. L. [1986]: Biological Science, New York: Norton.

Kitcher, P. [1984]: 'Species’, Philosophy of Science, 51, pp. 308-333.

Lewens, T. [2010]: 'The Natures of Selection', British Journal for the Philosophy of Science, 61 (2), 313-333.

Lewontin, R. [1970]: 'The Units of Selection', Annual Review of Ecology and Systematics, 1, 1-18. 
Lewontin, R. [1978]: ‘Adaptation’, Scientific American, 293, pp. 212-228.

Lloyd, E. [1988]: The Structure and Confirmation of Evolutionary Theory, New York: Greenwood Press.

Matthen, M. and Ariew, A. [2009]: ‘Selection and Causation', Philosophy of Science, 76, pp. 201-224.

Mayr, E. [1942]: Systematics and the Origin of Species, Columbia University Press.

Millstein, R. [2010]: 'The Concepts of Population and Metapopulation in Evolutionary Biology and Ecology', in Bell, Futuyma, Eanes, and Levinton (eds.), Evolution Since Darwin: The First 150 Years, Sunderland: Sinauer.

Millstein, R. [2009]: 'Populations as Individuals', Biological Theory, 4, pp. 267-273.

Millstein, R. [2006]: 'Natural Selection as a Population-Level Causal Process', British Journal for the Philosophy of Science, 57, pp. 627-653.

Neander, K. [1996]: 'Swampman Meets Swampcow', Mind and Language, 11, pp. 118-129.

Otsuka, J., Turner, T., Allen, C. and Lloyd, E. A. [2011]: 'Why the Causal View of Fitness Survives', Philosophy of Science, 78 (2), pp. 209-224.

Okasha, S. [2006]: Evolution and the Levels of Selection, Oxford University Press.

Pearl, J. [2000]: Causality, Cambridge: Cambridge University Press.

Reisman, K. and Forber, P. [2005]: 'Manipulation and the Causes of Evolution', Philosophy of Science, 72, pp. 1113-23. 
Reydon, T. and Scholz, M. [forthcoming]: 'Searching for Darwinism in Generalized Darwinism', British Journal for the Philosophy of Science.

Root, M. [2003]: 'The Use of Race in Medicine as a Proxy for Genetic Differences', Philosophy of Science, 70, pp. 1173-1183.

Rundle, H. D., Nagel, L., Boughman, J. W . and Schluter, D. [2000]: 'Natural Selection and Parallel Speciation in Sympatric Sticklebacks', Science, 287, pp. 306-308.

Sober, E. [2011]: 'Realism, Conventionalism, and Causal Decomposition in Units of Selection: Reflections on Samir Okasha's Evolution and the Levels of Selection', Philosophy and Phenomenological Research, 82, pp. 221-231.

Sober, E. [1984]: The Nature of Selection, Cambridge: MIT Press.

Sober, E. and Wilson, D. S. [1998]: Unto Others: The Evolution and Psychology of Unselfish Behavior, Cambridge: Harvard University Press.

Sober, E. and Lewontin, R. [1982]: 'Artifact, Cause and Genic Selection', Philosophy of Science, 49, pp. 157-180.

Stephens, C. [2004]: 'Selection, Drift, and the 'Forces' of Evolution', Philosophy of Science, 71, pp. 550-570.

Sterelny, K. [2009]: 'Philosophy of Evolutionary Thought', in Ruse and Travis (eds.), Evolution: The First Four Billion Years, Cambridge: Harvard University Press. 
Travis, J. and Reznick D. N. [2009]: ‘Adaptation’, in Ruse and Travis (eds.) Evolution: The First Four Billion Years, Cambridge: Harvard University Press.

Uyenoyama, M. and Feldman, M. W. [1980]: 'Theories of Kin and Group Selection: A Population Genetics Perspective', Theoretical Population Biology, 17, pp. $380-414$

Walsh, D. [2013]: 'Adaptation and the Affordance Landscape' in Pearce, Barker, and Desjardin (eds.), Entangled Life: Organisms and the Environment in the Biological and Social Sciences, Springer.

Walsh, D. [2010]: ‘Not a Sure Thing: Fitness, Probability, and Causation', Philosophy of Science, 77, pp. 147-171.

Walsh, D. [2007]: 'The Pomp of Superfluous Causes: The Interpretation of Evolutionary Theory', Philosophy of Science, 74, pp. 281-303.

Walsh D., Lewens T. and Ariew A. [2002]: 'The Trials of Life: Natural Selection and Random Drift', Philosophy of Science, 69, pp. 452-73. 


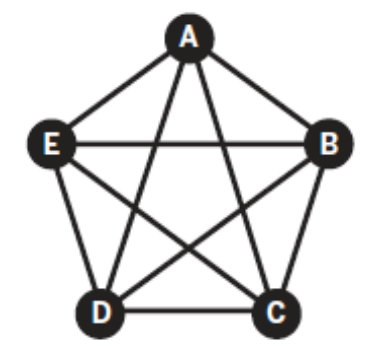

Figure 1a

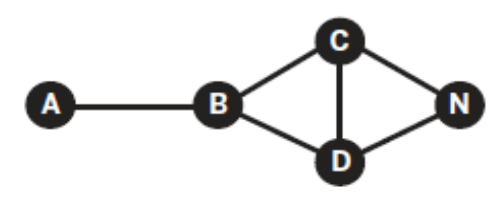

Figure 1b

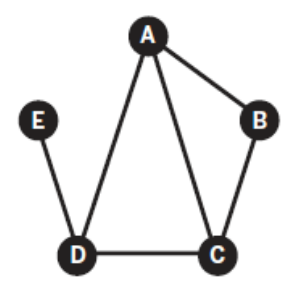

Figure 1c 


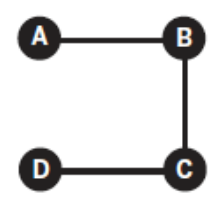

Figure 1d 


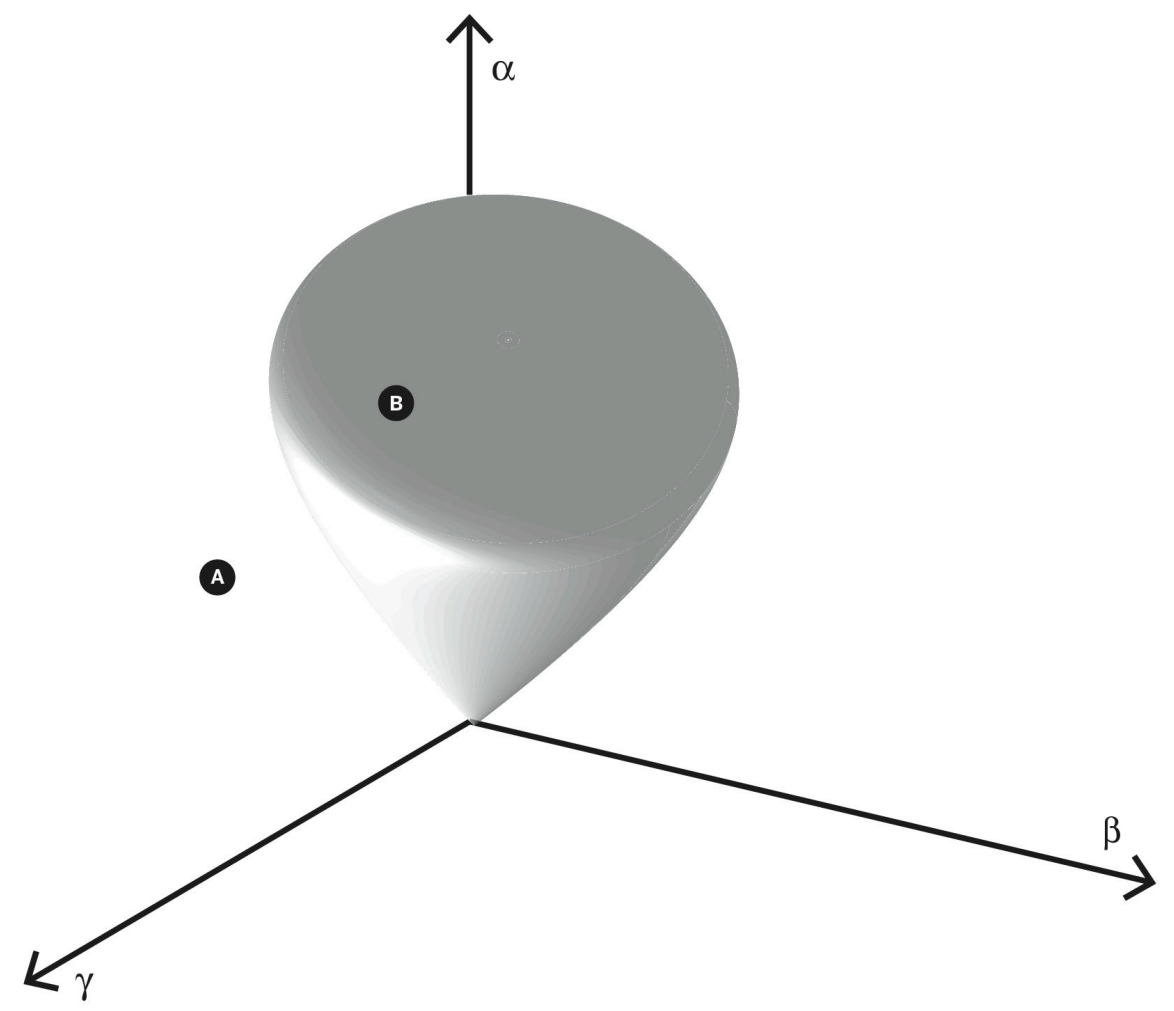

Figure $2 \mathrm{a}$. The shaded cone represents a population demarcation. Individual A is not in the population, while Individual B is in the population. 


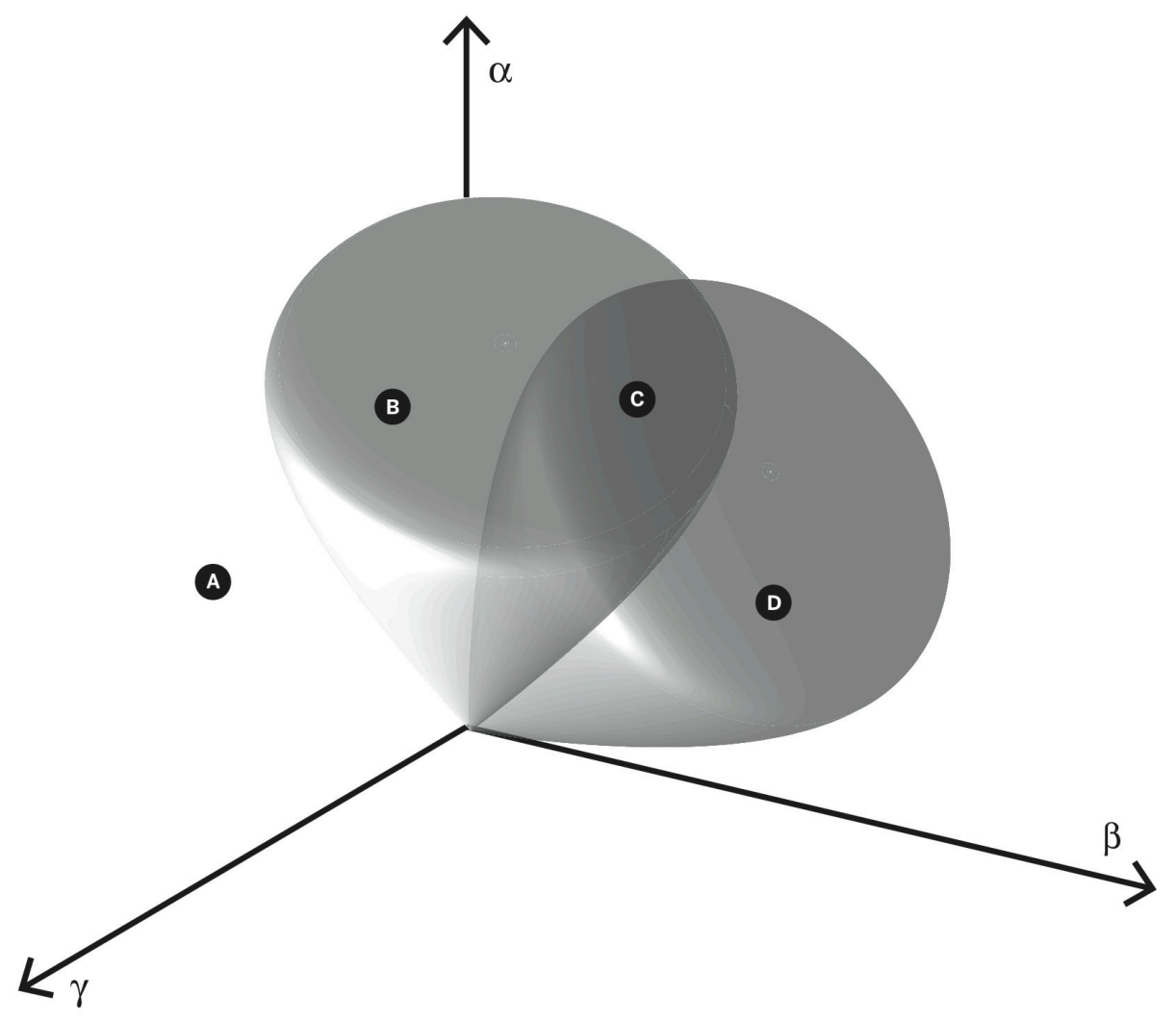

Figure $2 \mathrm{~b}$. The shaded cones represent two population demarcations. Individual A would not be in a population according to either demarcation; $\mathrm{B}$ and $\mathrm{C}$ would be in the same population according to the left-most demarcation but different populations according the right-most demarcation; $\mathrm{C}$ and $\mathrm{D}$ would be in the same population according to the right-most demarcation but different populations according the leftmost demarcation; B and D would not be in the same population according to either demarcation. 


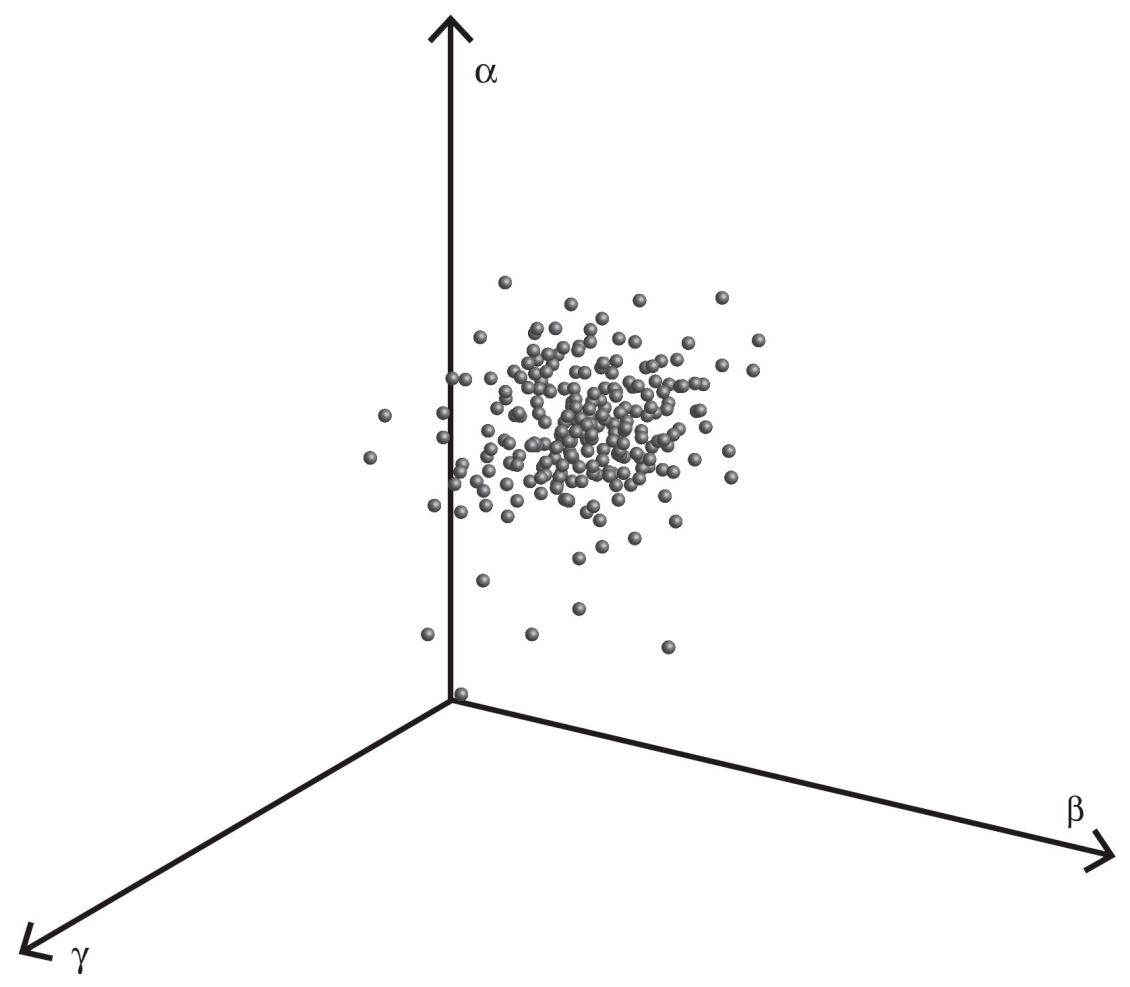

Figure 2c. Causal profiles of multiple individuals form a dispersed cloud, around which any sharp delimitation would in some respect be arbitrary.

Notes

${ }^{\mathrm{i}}$ Exceptions to such liberalism regarding the employment of various population conceptions might be based on normative considerations. For instance, some argue 
that the use of race as a variable for demarcating groups of people in biomedical research is not only biologically baseless but also potentially harmful; see, for example, (Root [2003]).

${ }^{\text {ii }}$ Population pluralism is akin to- and provides a generalized warrant of - a number of similar positions, including what (Godfrey-Smith [2009]) calls evolutionary nominalism, which holds that the grain of groupings (into coarse types or fine types) is not determined by biological facts; pluralism or anti-realism about species ((Kitcher [1984]), (Dupré [1993]), (Ereshefsky [1998])); and most recently what Barker and Velasco ([forthcoming]) call 'deep conventionalism' about evolutionary groups. In $§ 7$ I compare population pluralism to some of these similar positions.

iii I put aside for now the question of whether or not Lewontin is correct that these three conditions are in fact necessary and sufficient for evolutionary change by natural selection.

${ }^{\text {iv }}$ Requiring $C$ as a condition for biological populations has been defended, for example, by (Uyenoyama and Feldman [1980]) and (Millstein [2009]). (Okasha [2006]) notes the role that $C$ plays in generating hierarchical structures in biology. (Millstein [2010]) presents an even more restrictive account: $C$ is not only required for population membership, but the causal interactions must be much higher between members of a population than between any one of those members and organisms outside the population: 'the boundaries of the population are the largest grouping for 
which the rates of interactions are much higher within the grouping than outside' ([2010] pp. 67).

${ }^{\mathrm{v}}$ Under a widely held view regarding the concept of species, all the constraint achieved by $G$ can be achieved by $S$. That is because, as (Neander [1996]) notes, 'all the major contemporary schools in evolutionary biology agree that con-specifics must be united by descent' (pp. 119). Thus a concept of narrow biological population that requires $S$, and that assumes the view expressed by Neander (namely, that $S$ implies $G$ ), will by implication require $G$. See also (de Queiroz [1999]).

${ }^{\text {vi }}$ This view was originally developed in the classic paper by Lewontin ([1970]) and recently re-characterized by (Godfrey-Smith [2009]).

${ }^{\text {vii }}$ See also (Burt and Trivers [2005]), and of course the classic statement of the genecentric view in (Dawkins [1976]).

viii Bapteste, Bouchard, and Burian call such groupings "coalitions", and rightly note that some coalitions involve swapping of genetic material while other coalitions involve tight functional interactions with little or no exchange of genetic material ([2012]). See also (Dupré [2010]) and (Dupré [2012]).

ix This anti-typology forms the basis of what Godfrey-Smith refers to as 'evolutionary nominalism'. As I discuss below, what I refer to as 'population pluralism' is a broader notion, incorporating this anti-typology but extending such nominalism to groupings based on causal connections between individuals. 
${ }^{\mathrm{x}}$ To explicate this relation, plug in your favourite theory of causation. For example, under a probabilistic theory of causation, $\mathrm{A}^{\wedge} \mathrm{B}$ iff $\mathrm{p}\left(\mathrm{w}_{\mathrm{A}} \mid \mathrm{B} \& \mathrm{~K}_{\mathrm{i}}\right) \neq \mathrm{p}\left(\mathrm{w}_{\mathrm{A}} \mid \mathrm{K}_{\mathrm{i}}\right)$ or $\mathrm{p}\left(\mathrm{w}_{\mathrm{B}} \mid \mathrm{A}\right.$ $\left.\& \mathrm{~K}_{\mathrm{j}}\right) \neq \mathrm{p}\left(\mathrm{w}_{\mathrm{B}} \mid \mathrm{K}_{\mathrm{j}}\right)$ where $\mathrm{K}_{\mathrm{i}}$ is the state description of $\mathrm{i}$ which includes the complete set of causes relevant to the fitness of $A$ not including $B$, and $K_{j}$ is the state description of $\mathrm{j}$ which includes the complete set of causes relevant to the fitness of $\mathrm{B}$ not including A. See (Cartwright [1979]) for details. The right hand side of the biconditional is a disjunction because A can be causally related to B either because A has some causal influence on the fitness of B or because B has some causal influence on the fitness of $\mathrm{A}$ (or both). Conditionalizing on $\mathrm{K}$ is meant to prohibit common causes of the fitness of $\mathrm{A}$ and the fitness of $\mathrm{B}$ from constituting the ${ }^{\wedge}$ relation (more on this below).

${ }^{\mathrm{xi}}$ So, the ${ }^{\wedge}$ relation is not necessarily transitive (if $\mathrm{P}^{\wedge} \mathrm{Q}$ and $\mathrm{Q}^{\wedge} \mathrm{R}$ it is not necessarily the case that $\left.\mathrm{P}^{\wedge} \mathrm{R}\right)$.

${ }^{x i i}$ See (Irwin et al. [2001]) and (Irwin [2000]). For an introduction to Green warblers, including a map of the ring structure and audio samples of their songs, see Darren Irwin's website: <www.zoology.ubc.ca/ irwin/GreenishWarblers.html>.

xiii The classic statement is in (Mayr [1942]), and recent works supporting this include (Alexandrino et al. [2005]) and (Rundle et al. [2000]) (among many others).

${ }^{\text {xiv }}$ I am grateful to Eugene Earnshaw, Alex Marcellesi, and Ciprian Jeler for suggesting various versions of this example. 
${ }^{\mathrm{xv}}$ Barker and Wilson ([2010]) call a similar relation 'response cohesion', and rightly note that two individuals can share response cohesion while not interacting causally.

${ }^{x v i}$ An evolutionary fate is not something that happens merely to an individual, but rather to the lineage of which that individual is a member. Obviously two individuals could share the same fate-death — and not be part of the same biological population. This does not require or assume the $G$ condition, however, because two individuals can share the same evolutionary fate without sharing an evolutionary past (the automata referred to in $\S 3$ are a case in point).

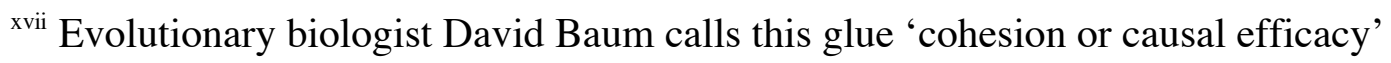
which individuals must have in order to be part of a 'functional unit' in evolution ([2009]); see also (Barker and Velasco [forthcoming]). For an insightful discussion of the notion of population in so-called Generalized Darwinism - that is, the construction of a general approach to the application of evolutionary theory to domains outside of biology — and specifically the argument that many alleged populations outside biology lack such glue and thus are not in fact 'biological populations' in the technical sense used here (popuations of individuals that can undergo evolution), see (Reydon and Scholz [forthcoming]).

${ }^{\text {xviii }}$ Indeed, it is these very gaps that biologists appeal to as part of their explanations for speciation events: such gaps disrupt species cohesion, and on an evolutionary time-scale the initial single species splits into disjoint species. 
${ }^{\text {xix }}$ Appealing to the notion of a shared evolutionary fate to determine which fitnessaffecting causes delimit populations would be circular (i.e., a population is a set of individuals that evolves together if and only if the set of individuals has a shared evolutionary fate) and methodologically useless (since we probably will not ever know about most evolutionary fates). My earlier appeal to shared evolutionary fates was meant to suggest that if the notion of a shared evolutionary fate is compelling, then so perhaps is $C$. Thus it would be unhelpful to identify the fine-grained fitnessaffecting causes that constitute $C$ by appealing to the notion of a shared evolutionary fate.

${ }^{\mathrm{xx}}$ For these reasons, appealing to the narrow biological population conditions $-G, P$, $T$, and $S-$ might be valuable or necessary methodological constraints on population delimitation. The epistemic problems associated with $C$ could be partially mitigated if one or more of $G, P, T$, and $S$ were correlated with the fine-grained causes that constitute $C$.

${ }^{\text {xxi }}$ As noted recently by (Walsh [forthcoming]), spatial metaphors abound in theoretical biology. The spatial device developed here has some affinity with those employed by (Godfrey-Smith [2009]).

xxii $\alpha, \beta$, and $\gamma$ might be causal relations that bear on reproductive interactions, resource access, and predator avoidance (for example). 
xxiii Which individuals? All other individual of all species in all times? Surely not. Some delimited class? But to provide a principled delimitation of the relevant set of individuals would be to answer the very question we are concerned with.

${ }^{\text {xxiv }}$ Specifying more precisely criteria for potentially excluding such topographies is beyond the scope of this paper.

${ }^{\mathrm{xxv}}$ Mayr put the point as follows: "normally the "population" is more or less an abstraction because there is a considerable interchange of individuals between neighboring populations, owing to the absence or incompleteness of physical barriers' ([1942]).

${ }^{x x v i}$ The statistical interpretation has been defended by (Walsh, Lewens, and Ariew [2002]), (Walsh [2007]), and (Matthen and Ariew [2009]). In virtue of the affiliation of several of these authors, the statistical interpretation has been referred to, somewhat in jest, as the Toronto Interpretation of natural selection. The causal interpretation, in contrast, has been promulgated by (Sober [1984]), (Stephens [2004]), (Reisman and Forber [2005]), and (Millstein [2006]) (among many others).

xxvii Gildenhuys argues that since population size is a central parameter of the dynamical equations in population genetics, if there can be multiple population sizes for a given natural system, then these equations would license inconsistent inferences, and thus population genetics would be a 'failed science'. Since population genetics is not a failed science-goes this argument-there cannot be multiple population sizes for a given natural system. But why think that inconsistent 
inferences implies a failed science? Famously, (Cartwright [1983], [1999]) and many others have argued that even our best sciences can license inconsistent inferences.

${ }^{\text {xxviii }}$ For a detailed discussion, see (Earnshaw [2012]).

${ }^{\text {xxix }}$ Okasha prefers the 'contextual approach' to decomposing group and individual selection. The relevant formalization is: $w \Delta z=\beta_{1} \operatorname{Var}(z)+\beta_{2} \operatorname{Var}(Z)$, where $\Delta z$ is the total change in trait frequency of the individual phenotype $(z), w$ is the individual fitness, $Z$ is the group phenotype, and the $\beta$ terms are regression coefficients. 